\section{Something to Crow About!}

$\mathbf{E}$ very summer, I start becoming a bit uneasy. When I got the privilege of serving as editor-in chief of JNCCN, I set some goals to measure my success. The metrics were pretty simple, and so was the plan to achieve at least one of them: by better focusing journal content, the number of submissions should rise. With more submissions, we could curate for better content. And publishing better content would raise the impact factor of the journal accordingly.

The impact factor report comes out in June or July, and for the weeks in advance of it, I start to worry. It's like waiting for your report card. Did I pass or fail? Honestly, I take this seriously! I'm proud of the journal and if I am not improving it, I should step aside.

If you are not familiar with the impact factor, let me fill you in. It was devised by Eugene Garfield, the founder of the Institute for Scientific Information, and the impact factor has been calculated annually for journals since $1975 .{ }^{1}$ It is based on the volume of citations that articles in the journal generate, and many see it as roughly akin to the quality of the journal. The formula used to calculate the impact factor ("IF" in the formula) of a given journal is below":

$$
\mathrm{IF}_{y}=\frac{\text { Citations }_{y}}{\text { Publications }_{y-1}+\text { Publications }_{y-2}}
$$

where $y$ represents the year being measured. So above, " $y$ " represents 2020 , and "y-1" and " $y-2$ " are 2019 and 2018, respectively. It stands to reason that the more times an article is cited, the more impact it has. How they go about gathering these data, on the other hand, is beyond me. The method is proprietary, so it can't be verified. I suspect software that can sort through PubMed to build the database is involved. I can't imagine humans doing this!

All that aside, I am happy to report that the impact factor for JNCCN has risen-again! In fact, the impact factor has been climbing steadily over the last few years:

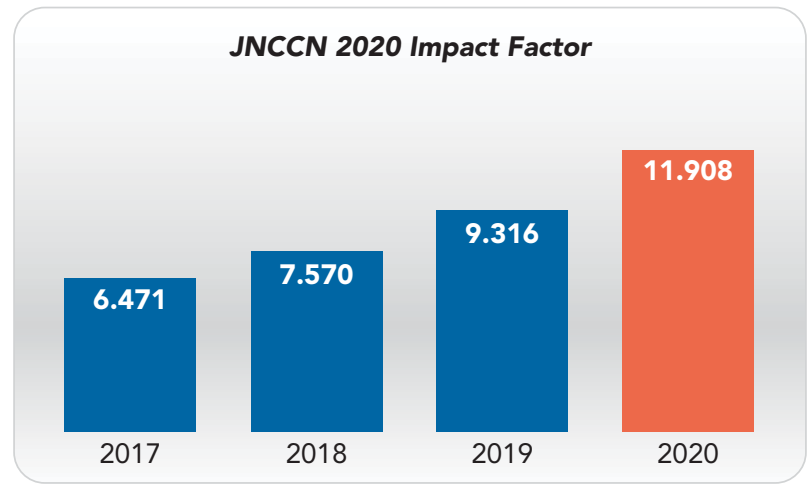

What a relief. My job here is secure ... at least until next year! And in case you are wondering whether this was accompanied by an increase in submissions, rest assured it was. The following graph shows the rise in submitted manuscripts over the past few years. Of course, 2020 might be a bit amplified due to the COVID-19 pandemic. With everyone stuck at home, they had more time to write up the data stashed on their desks!

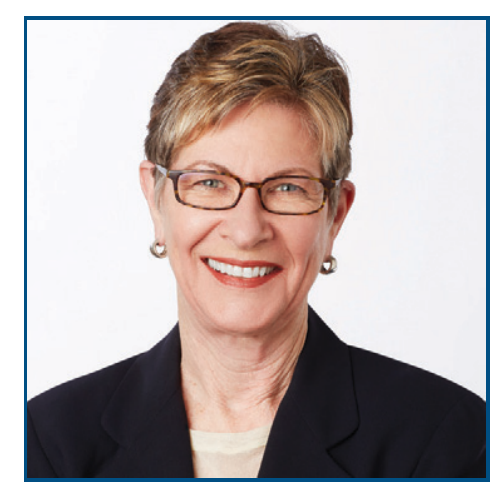

MARGARET TEMPERO, MD

Margaret Tempero, MD, is a Professor of Medicine and Director of the UCSF Pancreas Center and editor-in-chief of JNCCN. Her research career has focused on pancreatic ductal adenocarcinoma, especially in the area of investigational therapeutics. Dr. Tempero has served on the ASCO Board of Directors and as ASCO President. She currently serves on the ASCO Conquer Cancer Foundation Board. She codirected the AACR/ASCO Methods in Clinical Cancer Research and taught this course and similar courses in Europe and Australia. She was founding Chair of the $\mathrm{NCl}$ Clinical Oncology Study Section and served as a member and Chair of the $\mathrm{NCl}$ Board of Scientific Counselors Subcommittee A. She is a member of the Scientific Steering Committee and Chair of the Clinical and Translational Study Section for the Cancer Prevention \& Research Institute of Texas. She is or has been on the Scientific Advisory Boards of the Lustgarten Foundation, the Pancreatic Cancer Action Network, the V Foundation, The Alberta Canada Cancer Board, and the EORTC. She served as a member of the Oncology Drug Advisory Committee for the FDA. She has served as Deputy Director and Interim Director for the UNMC Eppley Cancer Center. She is Chief Emeritus of the Division of Medical Oncology at UCSF. She served as the founding Deputy Director and was later Director of Research Programs at the UCSF Helen Diller Family Comprehensive Cancer Center.

doi: 10.6004/jnccn.2021.0039

The ideas and viewpoints expressed in this editorial are those of the author and do not necessarily represent any policy, position, or program of NCCN. 


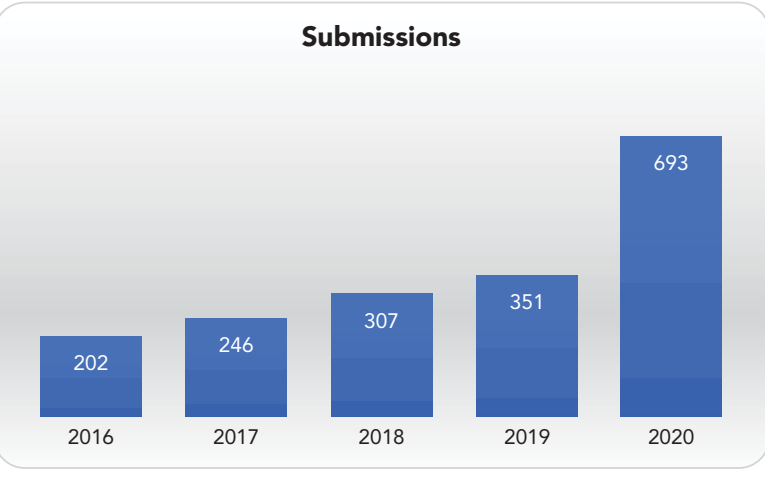

Of course, I do not do this alone. Many thanks and much gratitude are due to our Editorial Boards, both the Executive Editorial Board and the NCCN Guidelines
Editorial Board, who provide much guidance and wisdom especially when it comes to unsolicited letters and commentaries. And I'll conclude with a special shout-out to our editorial staff at NCCN. Their work ethic and commitment to excellence is unwavering. They make the complicated backstory look easy, and we are all grateful to them for all they do!

\section{References}

1. Masic I. The most influential scientist in the development of medical informatics (17): Eugene Garfield. Acta Inform Med 2017. 25:145

2. Journal of the National Comprehensive Cancer Network. 2020 Journal Citation Reports. Web of Science (Science ed.). Thomson Reuters. 2020

? WHAT DO YOU THINK? To submit a Letter to the Editor, email JNCCN@nccn.org or log into www.editorialmanager.com/JNCCN.

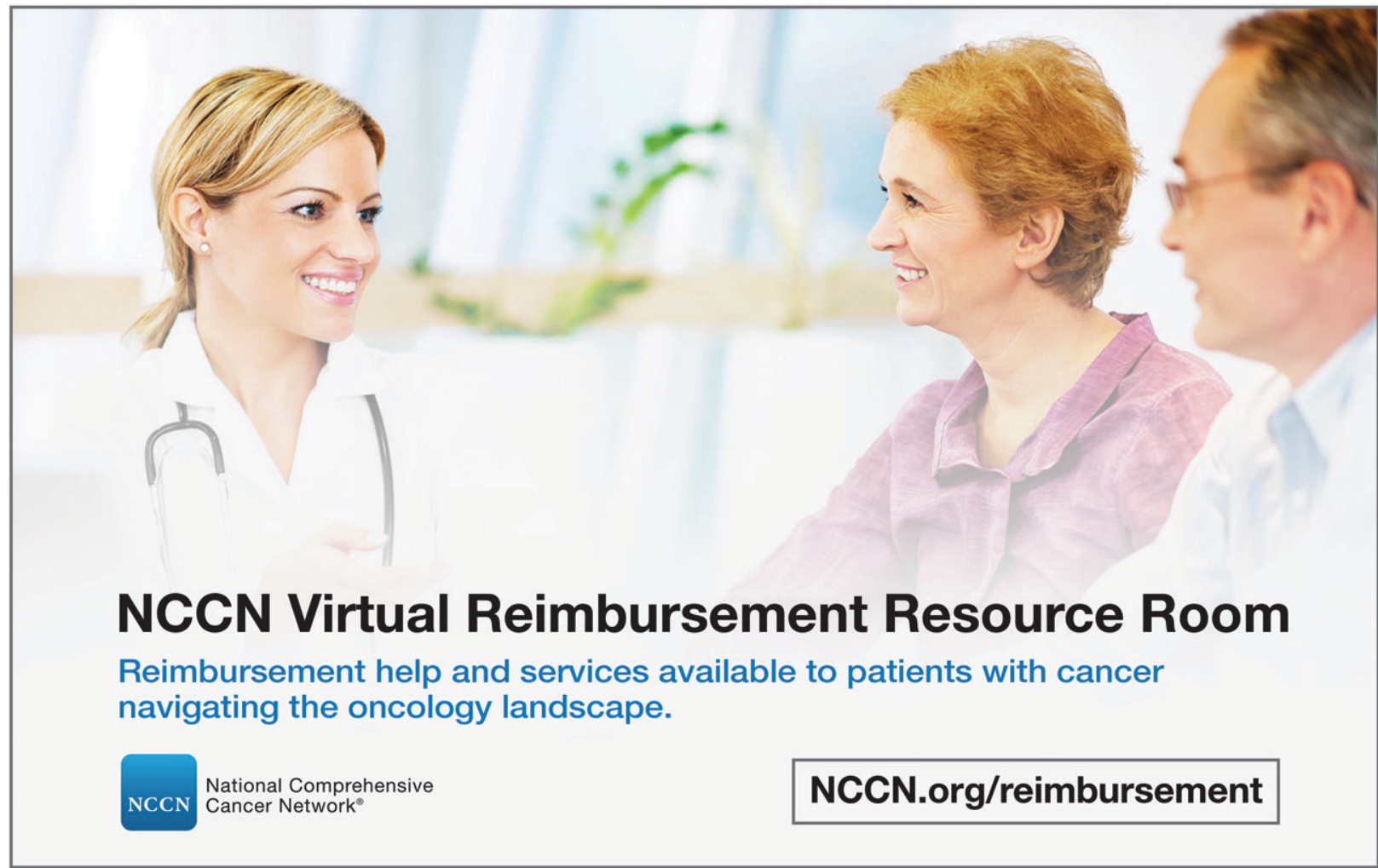

